\title{
A TELECOMMUNICATIONS DEVELOPMENT FRAMEWORK FOR TELECOMMUNICATIONS OPERATORS IN THE SADC
}

\author{
M.R. Fricke ${ }^{1}$ and J.K. Visser ${ }^{2}$ \\ Department of Engineering and Technology Management \\ University of Pretoria, South Africa \\ ${ }^{1}$ frickemr@telkom.co.za, ${ }^{2}$ krige.visser@up.ac.za
}

\begin{abstract}
Telecommunications development in Southern Africa is encouraged by government-level support and market trends. Various markets in the Southern African Development Community (SADC) region offer telecommunications operators' solid growth potential and the advantages of geographic diversification.

This paper presents a logical methodology for telecommunications operators (mobile or fixed) to guide network development and formulate strategy particular to the SADC. A proposed development framework gives structure and organisation to various aspects - business requirements, technology choices and market decisions - of a telecommunications business in Southern Africa. The overall model consists of four associated representations that fit logically into an enabling framework.
\end{abstract}

\section{OPSOMMING}

Die ontwikkeling van telekommunikasie in Suidelike Afrika word aangemoedig deur ondersteuning op regeringsvlak sowel as tendense in die mark. Verskeie markte in die Suidelike Afrika Ontwikkelings Gemeenskap (SAOG) streek bied aan verskaffers van telekommunikasiedienste 'n standvastige groeipotensiaal sowel as die voordele van geografiese diversifikasie.

Hierdie artikel beskryf 'n logiese metodologie vir telekommunikasie-operateurs (mobiele of vastelyn) om netwerkontwikkeling te lei en om strategie te formuleer wat uniek is vir die SAOG streek. Die voorgestelde ontwikkelingsraamwerk bied struktuur en organisasie aan verskeie aspekte, byvoorbeeld besigheidsbehoeftes, tegnologiekeuses en markkeuses, van 'n telekommunikasie-onderneming in Suidelike Afrika. Die totale model bestaan uit vier geassosieerde voorstellings wat op 'n logiese wyse verbind is om 'n totale raamwerk te vorm.

\footnotetext{
${ }^{1}$ The author was enrolled for the MEng (Technology Management) at the Department of Engineering and Technology Management, University of Pretoria
} 


\section{INTRODUCTION}

Countries in the greater Southern African area have collectively recognised, through bodies such as the SADC (Southern African Development Community), the need for organised, structured infrastructure development to improve socio-economic conditions. The facilitation of telecommunications infrastructure and services across the region is one of the objectives of the SADC. While a certain level of cross-country telecommunications development has already been achieved and the ICT (Information and Communication Technology) industry shows signs of rapid growth in "hotspots", service provision remains inadequate.

Acknowledging ICT infrastructure as both a crucial economic element and a necessary prerequisite for general infrastructure and industry development, the SADC organisation [1] has through more than 200 projects tried to raise the level of telecommunications and IT development in member countries.

The general objectives of SADC telecommunications policies are to provide affordable, efficient and high quality telecommunications services "for all", to create partnerships and an environment for sustainable ICT development (McCormick [2]). According to the SATCC (Southern African Transport and Telecommunications Commission) a teledensity of 25 - 30 lines per 100 persons is required to support the socio-economic activities of a nation that has transformed into a new economy. According to the ITU [3] the current teledensity is 6,4 fixed lines and 11,4 cellular lines per 100 people.

Therefore there exists government-level support, and to some extent even peer-pressure, to enable a common state of telecommunications policy that encourages infrastructure development across political borders in the region. Together with an expressed market need for connectivity and services (both internet and voice-based mobile communications), profitorientated industry players have been attracted to these de-monopolised spheres.

However, for telecommunications operators and international ICT business development managers to succeed with network expansion and service provision in these "new" markets, the economic and technological drivers of telecommunications in the SADC should be defined and properly understood within a framework which clearly positions a business plan or strategy to maximise the potential benefits. The aim of this paper is therefore to present a high-level "development framework" from which the derivation of a structured roadmap or strategy can be guided.

\section{FRAMEWORK CONTEXT AND DIRECTION}

Several technological and economic factors can be said to have driven change in the world ICT markets over the past decade. These trends, as well as those experienced in the SADC region, give rise to the current situation. Understanding these factors gives context to and yields understanding of operations in the network deployment area. These factors are briefly discussed below. 


\subsection{Economic Factors}

\subsubsection{Beyond the bubble}

Worldwide, the ITU reports the total revenues of the telecommunications industry in 2003 will be approximately US\$ 1,37 trillion, which is the highest amount ever, with 1,2 billion fixed lines and 1,3 billion mobile phones. Players in mature markets have then experienced traffic and subscriber growth, despite the pall hanging over the industry following the bursting of the "telecoms bubble". However, some practices in the late 1990's have resulted in fundamental problems with certain operators' businesses, which required immediate remedy. These include debt mismanagement, fraud, bankruptcy and vast unrestrained spending based on inaccurate traffic demand projections. The unnecessary spending (expanding core network capacity way beyond what was required and purchasing the overly expensive, hyped-up 3G licences) forced many firms into debt positions, which were unrecoverable as data traffic forecasts proved insufficient to warrant (and pay off) the infrastructure. Increasing price competition in local markets resulted and, together with the "telecoms bubble" bursting, forced firms to cut costs, restructure networks and organisations, and eliminate debt.

However, a strategy based on better positioning to meet real demand (which is strong in certain spheres, such as broadband and mobile services) and a customer orientation approach to services has emerged. Companies that have focused on real global market needs, such as interconnecting dispersed offices (in the form of Virtual Private Networks, or VPN's), offering cellular access to various markets and IP-based value-added services have done well since 2001. However, for traditional operators to adjust to the demands of customers in the next 5 - 10 years, a transition must be made.

\subsubsection{The Southern African region}

Pertinent economic trends affecting SADC telecommunications is the de-monopolisation of state-owned or controlled industries; the liberalisation of markets occurring or having already occurred in SADC member states and privatisation of these and other enterprises. The combined effect of these effects ensures a progressively more "open" market to industry players and a competitive environment. The push for complete liberalisation of telecommunications markets and the collaborative attitude of SADC members towards trade, commerce and development has increased the probability of economic and technological advancement throughout the region.

The source of this "advancement" is generally provided by foreign businesses entering the markets. Players (both operators and service providers) are attracted by the proven growth potential of emerging markets, as evidenced by the fast uptake of cellular technologies and Internet services. Table 1 shows how the proliferation of mobile, fixed line and Internet has progressed since 1995 in SADC member states (ITU [3]).

In 1995 South Africa had about 83\% of the fixed telephone lines in the SADC region and this reduced to $79 \%$ in 2002; an indication that the other countries are speeding up their installations. In 1995 South Africa had 95\% of the mobile subscribers and this decreased to $79 \%$; also an indication that the other SADC countries are improving gradually. The average compound annual growth rate for fixed lines in the period 1995 - 2002 was 7\%, while the 
annual growth rate for mobile subscribers in the same period was $97 \%$, clear indication that mobile communications will dominate the market in the near future.

\begin{tabular}{|c|c|c|c|c|c|c|c|c|c|c|c|c|c|}
\hline \multirow{3}{*}{ Country } & & \multicolumn{4}{|c|}{ Main telephone lines } & \multicolumn{4}{|c|}{ Cellular mobile subscribers } & \multicolumn{4}{|c|}{ Internet } \\
\hline & & \multicolumn{2}{|c|}{$\times 1000$} & \multirow[b]{2}{*}{$\begin{array}{c}\text { CAGR } \\
(\%)\end{array}$} & \multirow{2}{*}{$\begin{array}{l}\text { per } 100 \\
\text { inhab } \\
\text { in } 2002\end{array}$} & \multicolumn{2}{|c|}{$\times 1000$} & \multirow[b]{2}{*}{$\begin{array}{c}\text { CAGR } \\
(\%)\end{array}$} & \multirow{2}{*}{$\begin{array}{c}\text { per } \\
100 \\
\text { inhab. } \\
\text { in } \\
2002 \\
\end{array}$} & \multirow{2}{*}{$\begin{array}{l}\text { Total } \\
\text { hosts } \\
2002\end{array}$} & \multirow{2}{*}{$\begin{array}{l}\text { Hosts } \\
\text { per } \\
10000 \\
\text { inhab }\end{array}$} & \multirow{2}{*}{$\begin{array}{c}\text { Users } \\
2002 \\
\times 1000\end{array}$} & \multirow{2}{*}{$\begin{array}{c}\text { per } \\
10000 \\
\text { inhab } \\
\text { In } \\
2002 \\
\end{array}$} \\
\hline & & 1995 & 2002 & & & 1995 & 2002 & & & & & & \\
\hline Angola & & 52.7 & 85 & 7.1 & 0.61 & 2 & 130 & 81.6 & 0.93 & 8 & 0.01 & 41 & 29.42 \\
\hline Botswana & $*$ & 59.7 & 142.6 & 15.6 & 8.48 & & 415 & & 24.13 & 1273 & 7.57 & 50 & 297.47 \\
\hline DRC & $*$ & 36 & 20 & -9.3 & 0.04 & 8.5 & 150 & 61.4 & 0.29 & 134 & 0.03 & 6 & 1.14 \\
\hline Lesotho & & 17.8 & 34 & 9.7 & 1.57 & & 92 & & 4.25 & 60 & 0.28 & 5 & 23.15 \\
\hline Malawi & & 34.2 & 73.1 & 11.4 & 0.7 & 0.4 & 86 & 116.8 & 0.82 & 22 & 0.2 & 27 & 25.87 \\
\hline Mauritius & & 148.2 & 327.2 & 12 & 27.3 & 11.7 & 350 & 62.4 & 28.91 & 3462 & 28.6 & 180 & 1487 \\
\hline Mozambique & $*$ & 59.8 & 89.5 & 6.9 & 0.51 & & 152.7 & & 0.86 & 16 & 0.01 & 30 & 16.99 \\
\hline Namibia & $*$ & 78.5 & 117.4 & 6.9 & 6.43 & 3.5 & 150 & 71.1 & 8 & 4632 & 25.36 & 45 & 246.33 \\
\hline Seychelles & $*$ & 13.1 & 21.4 & 8.5 & 26.11 & 0.1 & 44.1 & 209.7 & 53.87 & 262 & 31.99 & 9 & 1098.9 \\
\hline South Africa & & 4002.2 & 4895 & 2.9 & 10.77 & 535 & 12081 & 56.1 & 26.58 & 238462 & 53.51 & 3100 & 682.01 \\
\hline Swaziland & & 21.1 & 35.1 & 7.5 & 3.4 & & 63 & & 6.1 & 1142 & 11.2 & 20 & 193.8 \\
\hline Tanzania & $*$ & 90.3 & 148.5 & 8.6 & 0.44 & 3.5 & 427 & 122.7 & 1.27 & 1478 & 0.44 & 100 & 29.77 \\
\hline Zambia & & 76.8 & 88.5 & 2 & 0.83 & 1.5 & 139.1 & 90.2 & 1.3 & 1095 & 1.03 & 52.4 & 49.01 \\
\hline Zimbabwe & & 152.5 & 287.9 & 9.5 & 2.47 & & 353 & & 3.03 & 3494 & 3.04 & 500 & 429.75 \\
\hline Total SADC & & 4842 & 6365 & 7.1 & 6.4 & 566.2 & 14632 & 96.9 & 11.4 & 255540 & 11.6 & 4165 & 329.3 \\
\hline
\end{tabular}

*: 2001 figures used in place of unavailable 2002 figures

CAGR: Compound annual growth rate, \%

Table 1: SADC Telecommunications Statistics (Source: ITU [3])

\subsubsection{Market entry modes}

The economic factors discussed in the previous section have led corporations to aim to capture a portion of the large potential market in some parts of Africa. Reasons for geographical expansion into emerging markets in the post-bubble telecommunications world can be distilled into the following main ideas:

- Diversification of risks, be they geo-political or technological.

- Higher general growth prospects offered by foreign markets. The cellular industry is under pressure to maintain its high subscriber growth rate, and since a saturation point is logically going to be reached, emerging markets represent a way to achieve this.

- To leverage existing knowledge and expertise in new markets and thereby increase the return on intellectual property.

- The liberalised or free-market state which is coming into existence intensifies economic and industry activity, driving demand for communication and information services, which opens the market to various service providers and ICT players. (Sarkar, et al [4]) 
Expansion can be achieved through various entry modes into new markets, the most prominent in this case being direct entry through joint ventures, strategic alliances, mergers and acquisitions, purchasing a firm in the target market and establishing Greenfield operations (Kogut et al [5]). Empirical studies show telecommunications companies expand abroad mainly through alliances and consortia. (Sarkar, et al [4])

The choice of entry mode affects the risks, opportunities and profit potential of the enterprise. In joint ventures and alliances, the most prolific telecommunications expansion vehicle, this entry choice has certain implications (expressed in brackets) to the following risks:

- The level of company control and decision-making (alliances mean the company has a high degree of control over foreign operations and control risk is reduced).

- Country risk, which is political and business uncertainties ("country risk" is maximised when entry mode is "direct entry", though joint ventures can reduce the political aspect). (Gronroos [6])

- Profit potential (entry modes have different profitability models, with complementary joint venture operations providing the highest profit. (Pan, et al [7])

- National culture of the target market (the level to which a firm understands differences and cultural behaviour) affects operations, with a joint venture a better entry mode than Greenfield operations. (Kogut, et al [5])

Joint ventures, alliances and Greenfield initiatives from operators who understand local culture are best-suited entry modes for telecommunications companies into the SADC. It is assumed that this direct, integrated or co-operative mode will generally be selected by operators for the Southern African market. The inheritance or adoption of some existing network infrastructure and the political and business uncertainties that exist in a region currently undergoing regulatory change, e.g. in the SADC, result in the most critical issues being technology rollout decisions, the regulatory environment and market evaluation.

\subsection{Technological Factors}

The so-called Next Generation Network (NGN), or provision of a multi-service network supporting converged services, is the general goal of new network and technology rollout. However, the support of various convergences of technology services has complex network evolution implications and wide-ranging consequences for both data transport and content. (Borés, et al [8]).

Obscuring the clear evolution to NGN networks are several issues. Network and information technology alternatives enabling multi-service provision are many and varied, especially at the service level (Achterberg et al [9]). Transport, service and core network technologies exist at various states of maturity, standardisation and operator acceptance. Further obfuscating technology rollout decisions are that legacy networks and technologies present in Southern African markets are often of different provenance with different levels of development and standardisation. These must combine with NGN technologies, which often originate from historically disparate domains. (Achterberg, et al [9]).

Adaptable, flexible technologies and network elements, which enable voice-data, service 
convergence and cost-effective access provision across different platforms is requisite. Given the level of complexity a rollout will entail, especially if the entry mode entails inheriting some existing network investment, a methodology that enables clear, structured technology decisions and evolution toward NGN architecture is necessary, while maximising revenues. The end goal offering direction to such a methodology is likely to be widespread broadband Internet Protocol (IP) adoption as a common network standard, as the advantages of this technology enable different approaches to network management. Technologies such as MultiProtocol Label Switching (MPLS) will decrease network complexity and enable operators to carry many different services over a single IP network.

\subsection{Market Factors}

The extent to which convergence forecasts and hype is accurate in the African markets, especially in the short- to medium-term, must be questioned. Reliable market information and demand forecasts, especially for advanced services, are almost nonexistent. This means operators will have to use their own usage statistics from existing services in the local market to forecast short-term future demand and respond to it on an ad hoc basis. As the venture matures, the forecast will become more reliable and the measurement cycle can be extended.

A managed network evolution and lean rollout of the multi-service networks, protecting any existing investment, must be the adopted operator methodology. Network rollout in the region should therefore employ robust, scalable and flexible elements, to adapt to demand where it is required.

Acknowledged problems with traditional telecommunications operators' businesses have the potential to be eliminated in these new markets (e.g. by "leapfrogging" technology) and better practices implemented. One such better practice is for the operator organisation to have a customer-focus orientation, as opposed to maximising return on investment. Designing business processes around a service orientation will more successfully allow the firm to address and to react to customer demands. On the business plane this essentially means the business plan must provide services that directly support the client's business cases. In this way the operator will address market perception, something that has plagued incumbents and telecommunications companies in Africa.

Another issue especially important in a largely technologically illiterate market is to offer services, and not to sell technologies. The product should be recognised as "airtime" or usage of a network, not ADSL or ISDN, which can confuse and alienate customers. Customers have in the past been offered hyped technologies which did not work as they had been led to believe, such as Wireless Application Protocol (WAP), which is not "a mobile version of the internet", as was touted. Operators should rather promote useful services.

\subsection{Contextual Framework}

The factors mentioned throughout section 2 need to be organised and integrated into a cohesive and unified expression or set of representations which will direct strategy formulation. The environmental context of the initiative, the overall strategy and the process through which the strategy must be defined, is represented by figure 1 . 


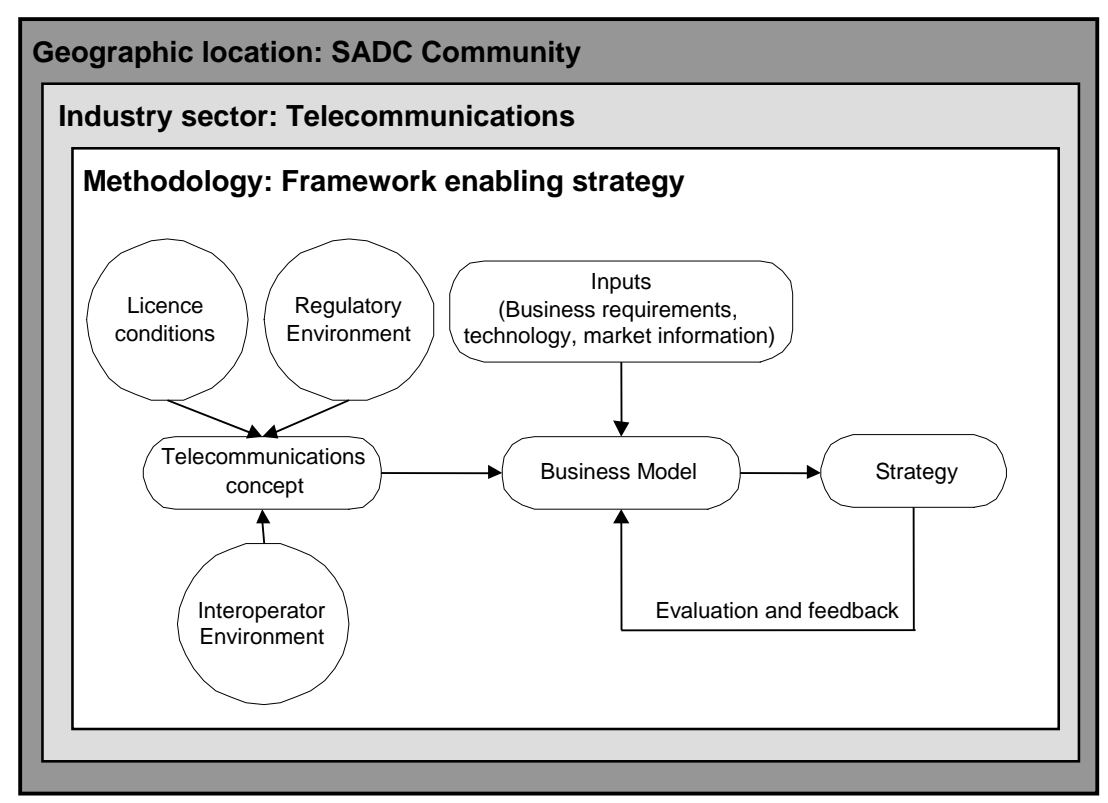

Figure 1: Contextual framework for enabling strategy

Various inputs, such as licence conditions, regulatory environment and interoperator environment, feed into the business model. The enterprise strategy is then derived from this business model.

\section{FRAMEWORK REQUIREMENTS:}

The development framework seeks to benefit telecommunications companies by mapping critical elements of the situation; providing structured organisation of network and technological elements to meet business needs, directing network evolution and aiding technology decisions, and maximising the market potential. The requirements should provide:

- A customer orientation to the services and implications to the network. (By utilising a customer-centric approach to strategy formulation and therefore network development, the service development and thus revenue opportunities are inherently aligned. Doing so ensures the network rollout actually satisfies the purpose for which it is built.)

- A methodology to evaluate various technologies and align them with the business needs. (Telecommunications is rife with various protocols, technologies and platforms for service creation. Therefore, a technology evaluation methodology which ensures the best-suited option for the intended market and purpose is selected.)

- A summary of relevant aspects of strategy application of the telecommunications business in the SADC. (Operating a network in the SADC is socially significant and politically relevant. Therefore, a set of various considerations as they apply to the strategy formulation process is required.)

- A framework, which enables the various ideas and provides structure and order to the roadmap. (A framework that enables the various aspects of conceptual models and provides sequence and order to all that has been discussed is required to "tie the strategy together" into a cohesive and logical context.) 


\section{PROPOSED DEVELOPMENT FRAMEWORK}

The overall development framework comprises four representations which are discussed in the following sections.

\subsection{Customer Visibility and Orientation}

Issues about the telecommunications business, which are most visible to the African customer and used to form perceptions of and determine satisfaction level with the operator, are summarised in figure 2 .

The four circles within the "customer visibility circle" are the major channels through which a customer will generally make judgments about the telecommunications company. The ellipses beyond the circle are the issues, which constitute each of these channels and are relevant to the operator.

Customer access: The market needs to be educated with respect to the technology and services available. Awareness of the possibilities of operator's services should be propagated. Any "fear" or negative perception of the technology that arises from ignorance of the technology should be immediately addressed. This will also increase the market presence and loyalty to a particular kind of service.

Complementary products and services, or network externalities, will encourage the market learning and participation in the telecommunications offerings. It is important to encourage participation of non-telecommunications company agents in new markets.

Offering pre-paid and similar "easy access" services is critical to the initial growth and success of various ICT services in Africa. The pre-paid concept eliminates many of the difficulties providers are faced with in Africa, such as the majority of customers not having one or more of a salary, street address, bank account or stable job, which is required for contract subscription.

Marketing and perception: The perception and marketing of services is obviously important, especially where the technology is (1) relatively new and unknown, and (2) the traditional marketing channels do not have widespread diffusion or usage characteristics similar to more mature markets.

However, a customer orientation which bases its edge on superior quality/ price ratios is likely to succeed (especially where there is no brand loyalty). The telecommunications market is generally divided into a high- and low-end segment. The great majority of business will be, at least initially, derived from the low-end segment. Thus, pricing and marketing are critical issues to be considered.

Also, an organisation orientated around providing service excellence as opposed to selling technology products is necessary. Projecting the operator as a customer-centric organisation is critical to the customer's perception. 


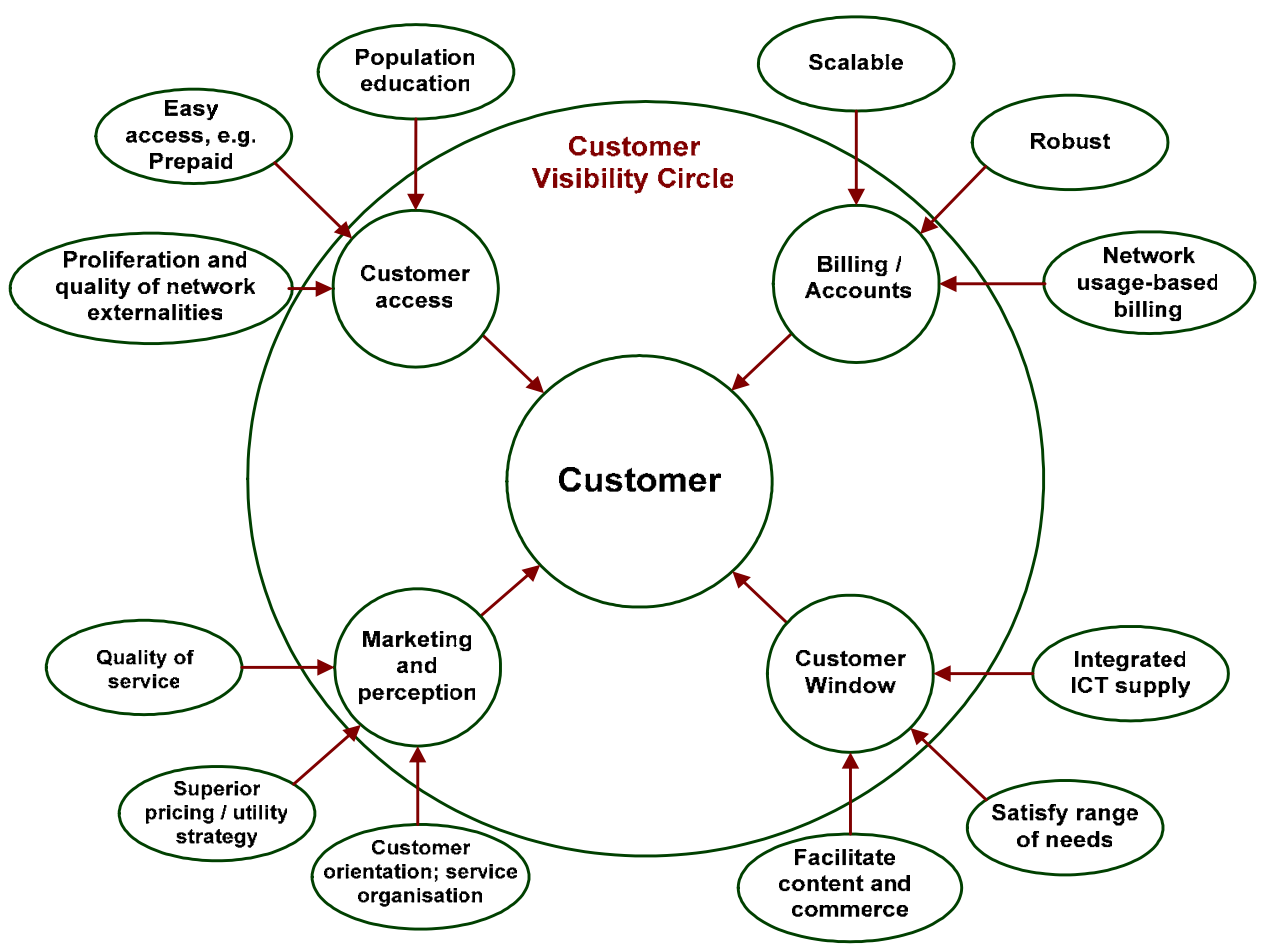

Figure 2: Customer visibility circle

Being perceived differently from the monopolistic enterprises which previously/ still dominate the telecommunications landscape is important for customer perception. The best way to do this is to operate a business which offers excellent quality of service, providing reasonable services where the previous corporation failed to do so and offer a competitive quality/ price basis to all products.

Customer window: The window through which the customer receives the ICT services contributes toward their entire perception of ICT, and consequently affects their spending and use of services. In developing countries, this is still fairly limited, and the customer's initial impression of services will therefore be amplified, as he/ she has nothing to counterbalance the impression or compare the standard with.

For maximum economic gain and customer utility, a provider must satisfy a range of the customer's needs. Doing so results in a higher return per customer, a better Return on Investment (ROI), increased chance of loyalty and "comeback" business, and the ability to sell other services.

This means the operator should, for example, provide or facilitate easy access to content and commerce, which the customer wants, together with the distribution channel. It should also facilitate a range of services - banking and entertainment services, for example - either through partnerships or directly.

Billing/ accounts: Billing elements should be scalable and robust. It should also be based on usage of resources, such as the volume of data transfer in Internet pipes - as opposed to time of connection - as this is often unreliable and a point of contention to the customer, especially in high-end markets. 


\subsection{Technology Decision Methodology}

A suggested methodology to evaluate technology applicability and ensure alignment with the business requirements is indicated in figure 3 below.

The methodology for reaching a decision on the technology to be used comprises a number of stages. Various inputs are required at the different stages of the process, i.e. market considerations, requirements and objectives of the company, and the alternative technologies that are available. Alternative technologies are defined and then screened to determine their applicability in the specific country or region. The alternatives are also evaluated against market issues and the objectives of the company. The technology decision methodology depicted in figure 3 is meant to guide decisions both on a large-scale network core level and for specific technology strategies in certain areas.

\subsection{Summary of Strategy Application Areas}

Further telecommunications considerations, some specific to the deployment area, and various strategy applications are shown in figure 4. Note that many issues overlap or apply to two or even all three designated areas. For example, a business consideration like "implement fraud and theft procedures" has a technological implication, but can also be argued as a business issue.

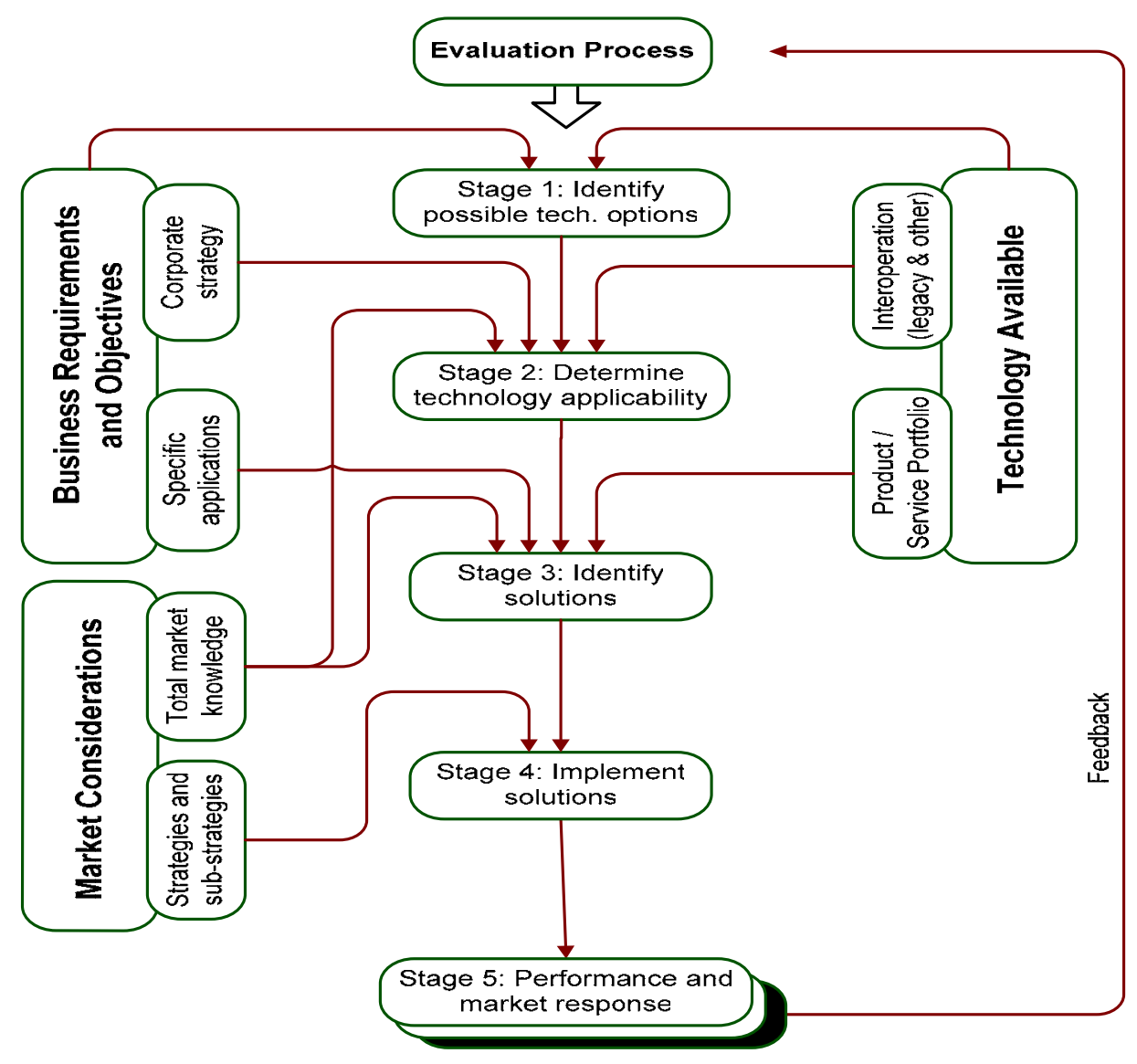

Figure 3: Technology decision methodology 


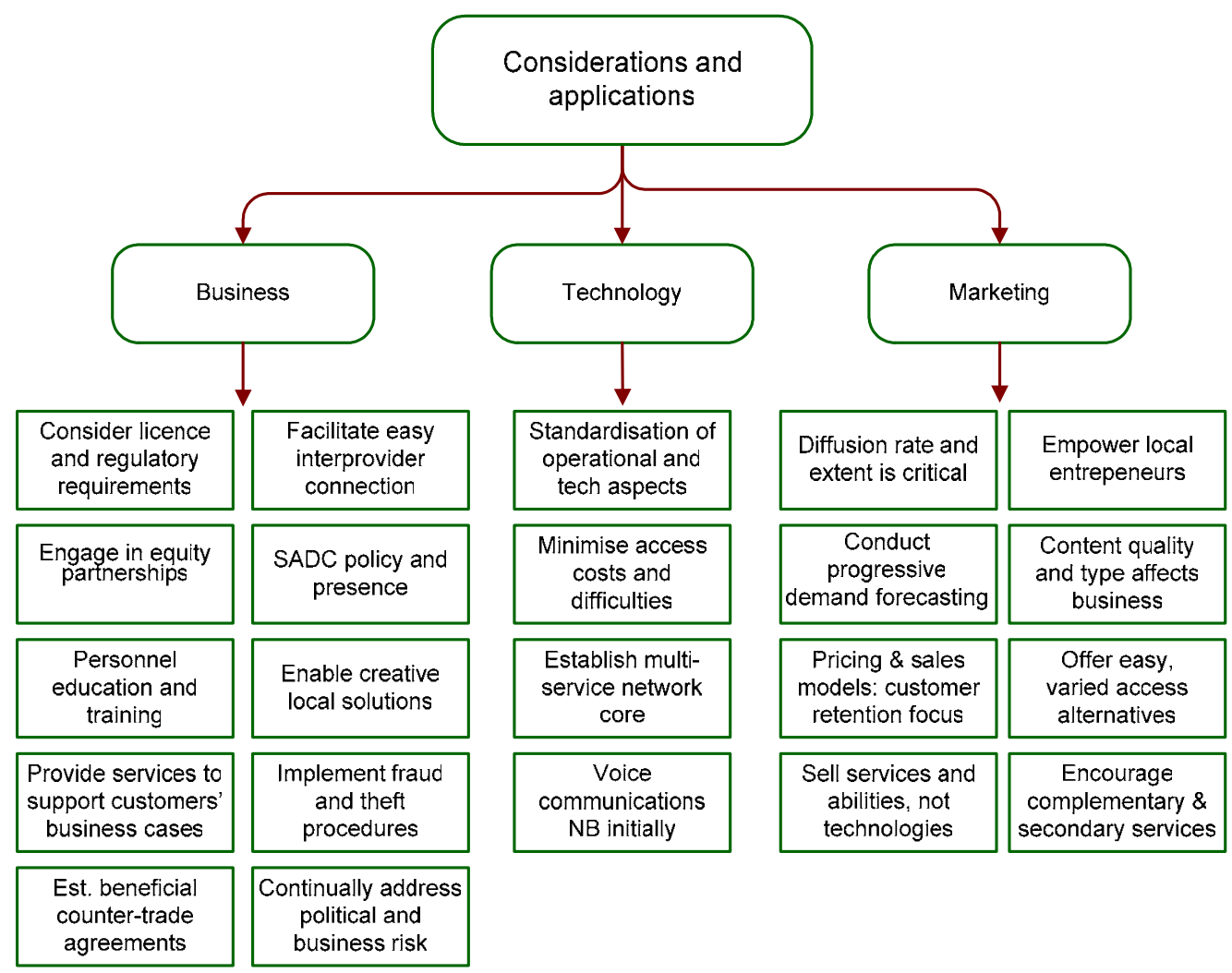

Figure 4: Business, technology and marketing considerations and applications

\subsubsection{Business considerations}

- The business should provide services to support its customer business requirements. For example, a solution to electricity payment problems could be to offer pre-paid account service. These accounts could then be "topped up" using mobile phones when necessary, and so the mobile operator should provide this facility.

- Implement anti-fraud and anti-theft of network access processes. These could range from watchdog software programmes identifying out-of-pattern account usage (thereby possibly detecting clip-on fraud), to network management processes set at certain operational tolerances and physical security measures at equipment sites.

- Education and training of local personnel is critical to the survival of the network, from both a cost and operational efficiency perspective. Telecommunications is still run by people and the level of skills of these employees often determines the quality of service rendered.

- Enabling creative local solutions is important. Operators, especially foreign, often do not allow for potentially successful but unconventional solutions to problems such as providing access to poor rural areas in their business models. Speeding the rate of market adoption and brand presence in the new market can be accelerated by enabling (sometimes temporary) alternative sales vehicles.

- Engaging in equity partnerships could be important to establish insight into the local market, credibility, and smooth the license procedure (where, for example, the local government wants to involve local companies). It can also reduce political risk. 
- Counter-trade agreements are usually required of business in foreign markets. Operators must consider the implications of such a constraint on revenue movement on their global operations. Creating trade relationships, which directly benefit the operator, such as establishing local equipment supplier depots (assuming there are no quality and manufacturing issues), would be an ideal arrangement from an operator perspective.

- Managing political and country risk is an active, ongoing concern that will evolve as the political and socio-economic landscape changes.

- The SADC presence should be considered insofar that the body has the potential to effect changes in the economic environment.

- Interoperational difficulties, whether technological or operational, affects the efficiency of operations. Interconnect agreements have a large influence on pricing models. Adhering to set standards (such as the ITU Region 2 set) and enabling best practices will minimise these difficulties.

- The license requirements and regulatory environment are important inputs to the business model. Universal service access requirements may be applied.

\subsubsection{Technology considerations}

- Utilising standardised equipment and technological specifications is a prerequisite for a modern, cross-country telecommunications network.

- Minimising access costs, which are notoriously high and include EIA's (environmental impact assessments), servitude costs, backup power supplies and theft devices, must be pursued.

- Establishing a multi-service network core is essential for future data and voice services.

- Voice communications in relatively undeveloped nations will initially be of greatest demand. Data services and Internet usage are increasing but remain secondary to voice connectivity.

\subsubsection{Marketing considerations}

- The product diffusion rate and extent through the market determines the economic success of that product. Maximising this is a marketing priority.

- Focus on the local customer and sell the services that are actually needed.

- The type and quality of the content carried affects the transmission business (Borés et al [8]). Providing content that is desired and of good quality will result in more traffic over that transmission channel. Conversely, poor content or a lack of content will adversely affect traffic.

- Offering easy, varied access alternatives with low entry barriers is important in emerging markets.

- Pricing and sales models should be focused on customer retention. Whilst product pricing should probably be within any similar existing service price ranges, product differentiation on the basis of quality or some other aspect should be focused on creating brand loyalty rather that pure revenue maximisation. 
- Encouraging complementary services and network externalities results in a greater awareness of both services / industries, and is mutually beneficial to sales.

Figure 4 above therefore gives expression to some significant features of telecommunications business in Southern African markets.

\subsection{Overall Development Framework}

The three representations of figures 2 through 4 are given structure and order through an overall (enabling) framework which is shown in figure 5.

Critical initial inputs in the framework are the state of the local regulatory environment and licence conditions. De-monopolisation or de-regulation that occurred to allow competition entrance will have been a fairly recent event and the regulatory environment can therefore be unstable, is unproven and not necessarily independent or free from political meddling. The regulatory environment also plays a large part in interconnect agreements and the tariffs applied, which in turn affect pricing models. Licence conditions may include access provision to under-serviced areas.

Strategy formulation is guided by the above framework and includes the previous roadmaps in figures 2, 3 and 4. The expression of the strategy (the output of the framework) and its implied mode of implementation are divided into "actors", "information associations and relationships", "technological and operational domains" and "processes and methodologies". These aspects are discussed in some detail below:

Actors: The players or actors must be addressed and accounted for in a strategy. These include the regulator, partner companies, competition companies, the market/ customers and any other body or organisation which has the ability to affect the strategy. Also important in the African environment are actors like financiers and the IT industry, which can indirectly affect the performance of the telecommunications company.

Technological and operational domains: A telecommunications provider is large and complex, and can be considered from different perspectives. Configuring the business along domain business boundaries, rather than pure organisational differentiation, ensures the multiservice environment which best characterises telecommunications is most accurately understood. Technological domains include: access technologies; edge; core domain; voice services; data services; the CPE (Customer Premises Equipment) and network management domain. Operational domains are the customer domain; billing and accounting domain; product and portfolio domain; network domain; hardware technology domain; and software technology domain.

Processes and methodologies: The various business processes are the manner through which the corporate strategy is enabled and achieved. It consists of a sequential arrangement of business functions and processes that are integrated in a particular manner to achieve desired outcomes consistent with the strategy. 


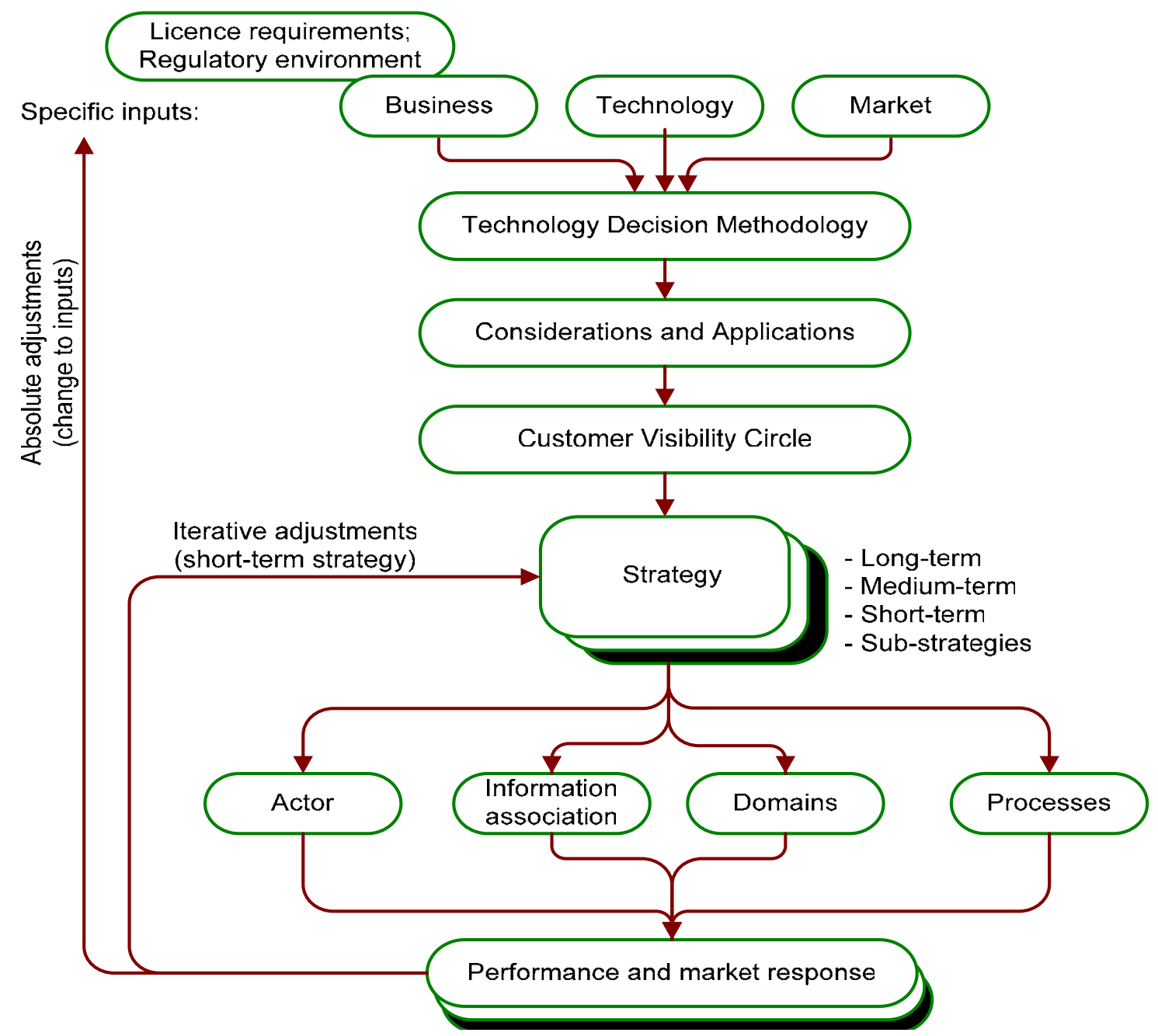

Figure 5: Overall development framework

Information associations and relationships: Informational associations and transactions occur between different elements of an entity. Formalised and informal relationships exist between various domain and functional areas. These relationships describe the communication and co-ordination of elements and their interdependencies.

A strategy often has to account for or formally describe the kind, frequency, extent and duration of information transfer in a relationship between entities. However, most relationships will simply exist and operate as part of the business. The business and actors should only be aware of the relationship in these cases.

\section{CONCLUSION}

The Southern African region represents a large potential telecommunications growth market, offering various advantages to foreign operators. With the existence of economic profit opportunities, a legitimate and accessible operating environment and demand for telecommunications development, telecommunications companies have entered or will enter 
these countries. However, the lack of a clear structure guiding this entrance and further development is potentially damaging for the long-term economic and social development, with the costs and consequences passed on to the customers. Therefore the formulation of an operator strategy framework or roadmap, which addresses all the issues pertinent to telecommunications development in a Southern African country, is required to enable the economic success of that operator and therefore also benefit the recipients of a successful network rollout.

This paper addresses strategy development for telecommunications infrastructure and services provisioning in the Southern African region. It proposes a development framework that enables the logical, ordered incorporation of various issues and gives form to the strategy expression.

Central to the framework is a technology decision methodology, guiding the evolution towards a NGN network core, whilst preserving existing investment and smoothing interoperation of elements. Alignment of services and products to the business plan and that of the customer needs is also addressed through the "considerations and applications" and "customer visibility circle" representations. The regulatory environment, license stipulations and interconnect agreements are important inputs to the framework. The output of the development framework is the formulation of a high-level strategy, and evaluation and feedback methodology.

The value and usefulness of the framework that was developed is therefore in identifying, ordering, structuring and guiding the overall methodology of strategy formulation of Southern African telecommunications. It provides a means of directing and understanding important parts of the business in a clear and logical manner. It also succeeds in applying and adapting the general concepts to the local environment, as well as identifying and dealing with issues particular to the Southern African region.

By acknowledging the significance of, and then addressing the issues specific to operating in the SADC, and focusing on the operations within an interoperator, multi-provider context with interactions across the value chain, the model encapsulates and expresses all aspects of the roadmap formulation process.

\section{REFERENCES}

[1] Southern African Development Community (SADC) 1998. Transport and Communications Report, Maputo, Mozambique

[2] McCormick, P.K., 2003. Telecommunication reform in Southern Africa: the role of the Southern African Development Community, Telecommunications Policy, 27(1), pp 95108

[3] International Telecommunications Union (ITU), 2003. Published statistics. www.itu.org 15 May 2003

[4] Sarkar, M.B., Cavusgil, S.T. and Aulakh, P.S., 1999. International expansion of telecommunication carriers: The influence of market structure, network characteristics, and entry imperfections, Journal of International Business Studies, 30(2), pp 361-382

[5] Kogut, B. and Singh, H., 1988. The effect of national culture on the choice of entry 
mode, Journal of International Business Studies, 19, pp 411-432

[6] Gronroos, C., 1999. International Strategies for services, Journal of Services Marketing, 13(4/5), pp 290-297.

[7] Pan, Y., Li, S. and Tse, D.K., 1999. The impact of order and mode of market entry on profitability and market share, Journal of International Business Studies, 30(1), pp 81104

[8] Borés, C., Saurina, C. and Torres, R., 2001. Technological convergence: A strategic perspective, Technovation, 21, pp 112-120

[9] Achterberg, R.A. and Hanrahan, H.E., 2001. Mapping Business and Technological Factors in Convergence, Intelligent Network Workshop, 2001 IEEE, 6-9 May

[10] Makhaya, G. and Roberts, S., 2003. Telecommunications in developing countries: reflections from a South African experience, Telecommunications Policy, 27(1), pp 4159 